\title{
Incorporating Service Quality into Yardstick Regulation: An Application to the Peru Water Sector
}

\author{
Chen Lin \\ Department of Economics \\ Lingnan University \\ Hong Kong, China \\ Tel: (852) 26167200 \\ Email: chen.lin@ln.edu.hk \\ Sanford V. Berg* \\ Department of Economics \\ Warrington College of Business Administration \\ University of Florida \\ PO Box 117142 \\ Gainesville, FL 32611-7142 \\ Tel: 1-(352) 392-0132 \\ Email: sberg@ufl.edu
}

February 29, 2008

\begin{abstract}
Yardstick regulation requires the utilization of benchmarking, a valuable tool for improving public service delivery, especially in developing countries where inefficiencies translate into negative health impacts and social unrest. However, benchmarking must account for both the cost and the quality of service. Using data from 38 Peruvian water utilities (1996 to 2001), the paper evaluates quality-incorporated firm performance and identifies changes in efficiency, technology (frontier), and service quality. The study utilizes the nonparametric data envelopment analysis (DEA) model, a preference structure model, and the quality-incorporated Malmquist productivity index in evaluating firm performance; the study discusses their implications for regulating state-owned enterprises.
\end{abstract}

JEL Classification: K23, L51, L95

Key Words: data envelopment analysis (DEA), Malmquist productivity index, service quality, yardstick regulation

\footnotetext{
* Corresponding author: Sanford Berg, Distinguished Service Professor in Economics and Florida Public Utility Professor, University of Florida. http://www.purc.ufl.edu .
} 


\section{Introduction}

Yardstick (benchmark) regulation for public utilities shows promise for improving the performance of regulated monopolies. Regulatory and institutional reforms in developed and developing countries during the past decade has stimulated interest in benchmarking as a tool for evaluating the effectiveness of the reforms, introducing competition through yardstick comparisons, and providing useful information about the "X factor" utilized in price cap regulation (Shleifer, 1985; Carrington et al., 2002). ${ }^{1}$ For instance, benchmarking is now part of the process of setting price caps in the UK. OFWAT, the water regulator in UK, uses econometric models to create efficiency bands and then set the $\mathrm{X}$ factor and price cap based on the efficiency bands (Saal and Parker, 2006).

The empirical literature on yardstick regulation contains some studies of the water sector in developing countries. Most of these studies have not considered the role of quality in the benchmarking processes due to data limitations and methodological issues. In an earlier study, Lin (2005) utilized a stochastic cost frontier to illustrate the importance of incorporating quality into performance comparisons. This study extends that work by: (1) providing more empirical evidence about firm performance and productivity and quality change of the water sector in developing countries (using Peru as a case study); and (2) proposing a benchmarking framework based on a preference-structure data envelopment analysis (DEA) model and the quality-incorporated Malmquist index; the approach allows regulators to apply their valuations of different quality dimensions to the benchmarking regulation they impose. The framework allows the decomposition of firm-level productivity change into efficiency change, technology change (frontier change) and quality change.

As an indicator of the firm-specific overall multi-dimensional quality change, the quality change indicator can provide useful information to regulators about the $\mathrm{Q}$ (quality) factor in the quality-dependent price cap regulation: $\mathrm{CPI}-\mathrm{X}+\mathrm{Q}$, where $\mathrm{CPI}$ is the consumer price index and $\mathrm{X}$ is the productivity offset. In addition to traditional performance indicators based on DEA and the Malmquist productivity index, this study utilizes the preference structure DEA model and quality-incorporated Malmquist productivity index. To the authors' knowledge, the preference structure DEA model has not been used in regulatory studies, and the quality-incorporated Malmquist productivity index has not been used in water studies to date (due to data availability issues). ${ }^{2}$

The results show that the preference structure DEA model can be used to reflect the weight given to quality in regulatory objectives. After imposing preference weights on the quality outputs (based on the current Peru water evaluation system), the correlation between the efficiency results of a basic model (only physical outputs) and a comprehensive model (both physical and quality outputs) is seen to be much lower than the correlation between the comprehensive model and a weighted-quality model (with the three quality variables weighted more heavily). Inclusion of quality indicators as desired outputs has a significant impact on firm efficiency rankings. In addition, analysis of the quality-incorporated Malmquist productivity index shows that on average productivity grew during 1998-1999, 2000-2001 and 1998-2001; productivity appears to have declined during 1999-2000. The average quality of service improved slightly during 1998-1999 and 1999-2000, but declined during 2000-2001. Overall, service quality improved very slightly from 1998-2001, indicating inadequate incentives for the publicly owned companies to improve their service quality under the regulatory scheme applicable for those years. The study also tests the multiplicative separability assumption in the process of decomposing the Malmquist index using both a ttest and nonparametric statistical test.

The rest of the paper is organized as follows: Section 2 provides a short literature review of benchmarking studies in public utility industries and reviews the reasons for taking quality variables into

\footnotetext{
${ }^{1}$ In practice, benchmarking is widely used in regulatory sectors such as the transportation sector in Costa Rica, the telecommunications sector in Hungary, the electricity and telecom sectors in the Netherlands, and the electricity sector in Norway and New South Wales (Parker et al., 2006). Burn et al. (2006) review the information revelation incentives for electricity utilities and the use of benchmarking in setting electricity distribution prices in Austria, the Netherlands, and Britain.

${ }^{2}$ Giannakis et al. (2005) and Estache et al. (2004) applied similar techniques to the electricity and railway industries, respectively.
} 
account in the benchmarking process. Section 3 provides background information regarding the Peru water sector and summarizes the current performance evaluation system. Sections 4 and 5 discuss the techniques used in the current evaluation and present empirical models and results.

\section{Literature Review}

Benchmarking studies based on parametric (e.g., stochastic frontier analysis) and non-parametric (e.g., data envelopment analysis) methods have been conducted in various infrastructure industries during the past few years. For example, Carrington et al. (2002) evaluate the relative utility performance in the Australian natural gas industry. Using DEA and SFA methods, Estache et al. (2004) and Farsi and Fillippini (2004) measure the efficiency of electricity distribution companies in South America and Switzerland, respectively. Lam and Shiu (2004) calculate the efficiency values and the efficiency change in China's electricity generation industry. Using data from Ukraine electricity distribution firms, Berg et al. (2005) find that private operators respond more aggressively to cost-plus regulation to increase shareholder value through cost inflation though privatization improved some dimensions of performance. Knittel (2002) checks the effect of alternative regulatory methods on the utility efficiency of the U.S. electricity distribution industry. For more detailed reviews, see the studies by Jamasb and Pollitt (2001) and Estache et al. (2005).

Non-energy network industries have also received attention. In telecommunications, Majumdar (1997) evaluates the effect of incentive regulation on the technical efficiency of U.S. local exchange carriers between 1988 and 1993. Uri (2001) uses the Malmquist productivity index to calculate productivity change due to the implementation of incentive regulation in telecommunications. In the water sector, Saal and Parker $(2000,2001)$ check the effect of privatization and regulation on productivity growth and the total cost of the water sector in England and Wales. They underscore the importance of using quality-adjusted outputs (adjusted by indices of the relative quality of drinking water and sewerage treatment). Saal and Parker (2006) employ a quality-adjusted panel input distance stochastic frontier to estimate productivity growth rates for the water operations of the water sector in England and Wales between 1993 and 2003. They further decompose the productivity change into efficiency change, technology change, and scale change. Wallsten and Kosec (2005) include several dimensions of quality in their comparison of privately and publicly owned water utilities in the U.S.: violations of the maximum levels of health-based contaminants and violations of monitoring and reporting regulations. Berg and Lin (2006) examine a methodological issue associated with benchmarking: the consistency of performance rankings based on non-parametric (DEA) and parametric (stochastic production frontier and distance function) methods (in the Peruvian context). Two service quality measures (coverage of service and continuity of service) are incorporated as outputs in the models. The present study adds the pass rate of chlorine tests as an additional quality indicator and focuses on how prioritizing objectives can be incorporated into the benchmarking process.

Most other water studies have not incorporated quality variables into the analysis, but examine the impacts of other factors. Cubbin and Tzanidakis (1998) and Ashton (2000) estimate water utility firm efficiency in United Kingdom. Estache and Rossi (2002) use 1995 data from 50 water companies in 19 Asian countries to explore the effects of ownership on utility performance. They do not find significant differences between private and public water utilities. However, Estache and Kouassi (2002) find empirical evidence supporting the view that private operators are more efficient than public operators in Africa. Corton (2003) uses OLS cost function to evaluate the efficiency of Peruvian water utilities. Tupper and Resende (2004) use DEA to develop efficiency scores for twenty Brazilian water utilities during 1996-2000 and propose a procedure for constructing a linear reimbursement rule that constitutes a yardstick competition mechanism. Kirkpatrick et al. (2006) find that private utilities in Africa are associated with better performance than are state-owned utilities based on DEA results but not in the stochastic frontier analysis (SFA) models.

As noted above, only a few studies focus on the water sector in developing countries and include quality elements in the benchmarking processes. There are two reasons for the inclusion of quality aspects 
into our study. First, if we ignore the quality aspects in the benchmarking, "low-cost, low quality" companies may be labeled as "efficient" companies, which may distort the original intention of benchmarking (Sappington, 2005). In addition, quality can be an important issue in total factor productivity (TFP). For instance, Saal and Parker (2001) show that the unadjusted TFP change in the U.K. water sector appears to have been extremely slow in recent years. However, quality has improved significantly because of the large increases in minimum standards, which required significant outlays. Thus, the use of unadjusted TFP change measures during this period understates actual TFP improvements (measured in a more comprehensive manner).

Second, service quality is an important issue in the water sector. According to the World Bank (2003), more than 1 billion people in the developing countries lack access to clean water, and almost 1.2 billion people lack adequate sanitation. An estimated 12.2 million people die every year due to the diseases directly related to drinking contaminated water. The World Commission on Water estimated that mitigating water and sanitation problems would require US\$600-800 billion between 2000 and 2010. Therefore, water regulators in developing countries may put extra weight on improving service quality and coverage when evaluating sector performance.

\section{Peru Water Sector and Its Performance Evaluation System}

Corton (2003) characterized the water sector of Peru as one with serious problems, including inadequate system maintenance, a high level of unaccounted-for water, excess staff, low metering rates, and low water quality. In order to effectively monitor the monopoly suppliers and improve their firm performance, in 1992 the Peru government created SUNASS (Superintendencia Nacional de Servicios de Saneamiento) to regulate water and sanitation services. SUNASS attempts to ensure that consumers receive the best possible drinking water and sewerage service, in terms of adequate quality, quantity, continuity, coverage, and fair price. Its functions include economic regulation, supervision, sanctions, setting rules/norms, and dispute resolution (between customers and service providers). This agency's funding comes from a $1 \%$ surcharge on the invoicing from the service providers. The agency's Board of Directors has five members: two from the First Ministry Office (one is appointed as Chairman), one from the Ministry of Finance, one from the Ministry of Housing, Construction and Sanitation, and another one from the Office of Fair Competition.

To promote better performance, SUNASS developed a Management Indicators System (MIS) with the help of the World Bank. The MIS collects data from utilities, making it possible to compare service providers. The expectation was that low efficiency companies would gradually improve in response to greater pressure to perform efficiently. SUNASS selected nine performance indicators and categorized them into four dimensions:

1. Quality of Service includes three variables: compliance with the residual chlorine rule, continuity of service, and percentage of water receiving chemical treatment.

2. Coverage of Service Attained consists of two variables: water coverage and sewerage coverage.

3. Management Efficiency reflects three variables: operating efficiency (a combination of continuity of service and the volume of water produced to serve each person at a connection), percentage of connections with meter installed, and the ratio of bills not yet collected to the total number of bills.

4. Managerial Finance Efficiency is defined by the ratio of direct costs and other expenses to revenues.

The first two broad areas of efficiency are intended to represent the interests of society. The third reflects the companies' performance, and the fourth represents the citizen-owner's perspective. In order to obtain a single measure of performance, each indicator expressed as a percentage is multiplied by its weight (equal weight=1) and added together to obtain a total score for each company. This total per company is divided by nine, the number of indicators, to get the final score. The emphasis on social concerns is evident in the greater number of indicators related to performance affecting society. 


\section{Methodology}

Efficiency measurement methods can be subdivided into parametric and non-parametric methods. The parametric methods of efficiency analysis rely on specified functional forms of production or cost functions; they utilize econometric techniques. Non-parametric methods use mathematical programming techniques and do not require specification of production or cost functions.

Both methods have been applied widely in different industries such as electricity, telecommunication, gas, and water. Berg and Lin (2006) examine the consistency of the performance rankings based on DEA and SFA models in the Peruvian context. They find that DEA and SFA distance functions yield similar rankings and have comparable success in identifying the best and worst performing utilities. ${ }^{3}$

Because DEA analysis can easily accommodate multiple inputs and multiple outputs simultaneously, it is employed as the analytic tool in this paper. ${ }^{4}$ DEA has been used in a number of recent water studies. For example, Thanassoulis (2000) reviewed DEA and its use in estimating potential cost savings at water companies in the context of the price review conducted by the regulator of water companies in England and Wales. Similarly, Tupper and Resende (2004) use DEA supplemented by econometric analyses to provide efficiency scores for twenty Brazilian state water and sewage companies.

\subsection{DEA Analysis: CCR and BCC Models}

Single-measure gap analysis is the simplest form of performance evaluation and benchmarking. For example, regulators in the water industry commonly use efficiency indicators, such as the number of workers per connection and the number of connections per 100 families, to assess utilities' performance. ${ }^{5}$ However, these measures are not good substitutes for efficiency frontiers, which recognize the complex nature of interactions between multiple inputs and multiple outputs. ${ }^{6}$ Suppose that m input items and $\mathrm{s}$ output items are selected. Let each decision-making unit $\mathrm{j}\left(D M U_{j}, j=1,2, \cdots, n\right)$ produce a vector of outputs $\left(y_{1 j}, y_{2 j}, \cdots, y_{s j}\right)$ by using a vector of inputs $\left(x_{1 j}, x_{2 j}, \cdots, x_{m j}\right)$. The output-oriented CCR (Charnes et al., 1978) model is expressed with a real variable $\phi$ and a non-negative vector

$$
\begin{aligned}
& \lambda=\left(\begin{array}{llll}
\lambda_{1} & \lambda_{2} & \ldots & \lambda_{n}
\end{array}\right)^{T} \quad \text { of variables as follows: } \\
& \phi^{*}=\max \phi \text { s.t. } \sum_{j=1}^{n} \lambda_{j} x_{i j}+s_{i}^{-}=x_{i o} ; \sum_{j=1}^{n} \lambda_{j} y_{r j}-s_{r}^{+}=\phi y_{r o} ; \lambda_{j} \geq 0
\end{aligned}
$$

\footnotetext{
3 This does not mean DEA and SFA always generate similar results. In some cases, the parametric and non-parametric methods do produce different results.

${ }^{4}$ The distance function can also accommodate multiple inputs and multiple outputs simultaneously (Coelli and Perelman, 2000). The distance function is generally expressed in flexible translog functional form because the Cobb-Douglas function imposes strong assumptions such as fixed returns to scale and a unitary elasticity of substitution. However, given the complexity of our models (3 inputs, 2 physical outputs and 4 quality outputs) and our modest sample size, translog would consume too many degrees of freedom (the model would contain 45 independent variables). Therefore, DEA models are used in this study. ${ }^{5}$ For instance, the high ratio of staff per connection in Peru may not indicate the inefficiency of the utility companies. It could be due to cheaper labor substituting for other inputs rather than over-staffing. Therefore, we need to use the multiple inputs/outputs frontier model to evaluate utility efficiency.

${ }^{6}$ DEA, the most typical non-parametric frontier method, is utilized here. DEA provides a mathematical programming method for estimating production frontiers and evaluating the relative efficiency of different decision-making units-here, water utilities. The advantages of the DEA model are that it does not require the specification of a functional form to be fitted, and can simultaneously accommodate multiple inputs and outputs. The technique also has its limitations: Rossi and Ruzzier (2000) show that the efficiency measures obtained with DEA can be very sensitive to the number of variables included in the model. As the ratio of the number of variables/sample size goes up, the ability of DEA to discriminate among firms is sharply reduced, because it becomes more likely that a certain firm will find some set of weights to apply to its outputs and inputs that will make it appear as efficient. Another limitation of the non-parametric approach is that the DEA models cannot take into account the effects of random noise or random error.
} 
(i $=1,2, \ldots, m ; r=1,2, \ldots, s ; j=1,2, \ldots, n)$.

where $D M U_{o}$ represents one of the n DMUs under evaluation, and $x_{i o}$ and $y_{i o}$ are the ith input and $r$ th output for $D M U_{o}$, respectively. $\phi^{*}$ represents the (output-oriented) efficiency score of $D M U_{o}$.

We define the input excesses $s^{-}$and the output shortfalls $S^{+}$and identify them as "slack" vectors by:

$$
s_{i}^{-}=x_{i o}-\sum_{j=1}^{n} \lambda_{j} x_{i j} ; \mathrm{s}_{\mathrm{r}}^{+}=\sum_{j=1}^{n} \lambda_{j} y_{r j}-\phi^{*} y_{r o}
$$

The CCR model is built on the assumption of constant returns to scale (CRS) of activities. According to the BCC (Banker et al., 1984) model, if the condition $\sum_{j=1}^{n} \lambda_{j}=1$ is added, then variable returns to scale (VRS) are possible. For detailed information about CCR and BCC models, readers are referred to Cooper et al. (2004).

\subsection{DEA with Preference Structure}

The basic DEA models (CCR and BCC) are called radial efficiency measures, because these models adjust all inputs, or outputs, of a DMU by the same proportion. Färe and Lovell (1978) introduce a non-radial measure that allows a non-proportional reduction in inputs, or non-proportional augmentation of outputs. The output oriented CRS model can be expressed as:

$$
\max \frac{1}{s} \sum_{r=1}^{s} \phi_{r} \text { s.t. } \sum_{j=1}^{n} \lambda_{j} x_{i j}+s_{i}^{-}=x_{i o} ; \sum_{j=1}^{n} \lambda_{j} y_{r j}=\phi_{r} y_{r o} ; \phi_{r} \geq 1 ; \lambda_{j} \geq 0 ; s_{i}^{-} \geq 0 \text {. }
$$

In the standard DEA formulations, DMUs are in a position to choose the weights to be assigned to each input and output in a way that maximizes its efficiency, subject to the system of weights being feasible for all other DMUs. This freedom of choice is equivalent to assuming that no input or output is more important than any other (Cooper et al., 2004). In our case, it is necessary to construct a model that integrates the regulator's preferences and value judgments in DEA models and to estimate the targets according to these preferences ${ }^{7}$. Following Zhu (1996), the output-oriented weighted non-radial preference model can be expressed as:

$$
\max \frac{\sum_{r=1}^{s} B_{r} \phi_{r}}{\sum_{r=1}^{s} B_{r}} \text { s.t. } \sum_{j=1}^{n} \lambda_{j} x_{i j}+s_{i}^{-}=x_{i o} ; \sum_{j=1}^{n} \lambda_{j} y_{r j}=\phi_{r} y_{r o} ; \phi_{r} \geq 1 ; \lambda_{j} \geq 0 ; s_{i}^{-} \geq 0 ; B_{r} \geq 0 \text {, }
$$

where $B_{r}(\mathrm{r}=1,2, \ldots, \mathrm{s})$ are user-specified preference weights that reflect the relative degree of desirability of the adjustments of the current input and output levels, respectively. The greater is the weight $B_{r}$, the higher is the priority that $\mathrm{DMU}_{\mathrm{j}}$ would be expected to give to increase its $\mathrm{r}^{\text {th }}$ output. The basic non-radial DEA model (3) is a special case of (4) when all the $B_{r} \quad(\mathrm{r}=1,2, \ldots, \mathrm{s})$ are equal. The preference weights can be obtained by using Delphi-like techniques or an analytic process yielding some value hierarchy.

\footnotetext{
${ }^{7}$ In the current SUNASS evaluation scheme, the emphasis on social concerns is evident in the greater number of indicators that are related to performance affecting society (coverage and treated water having implications for public health). This implicit weighting suggests that the regulator may prefer that companies improve service quality rather than cut their costs. Therefore, the regulator may want the benchmarking scheme to induce the DMUs to place greater emphasis on service quality outputs.

${ }^{8}$ For instance, Lynch et al. (1994) use hierarchical conjoint analysis to derive weights for dimensions of telephone service quality; the methodology could also be applied to water and other infrastructure industries.
} 


\subsection{Malmquist Productivity Index}

So far, the focus has been on evaluating firm performance at a point in time. To evaluate the efficiency change over time, the Malmquist productivity index is used in the following analysis: ${ }^{9}$

Suppose each $D M U_{j}(j=1,2, \cdots, n)$ produces a vector of outputs $y_{j}^{t}=\left(y_{1 j}^{t}, \cdots, y_{s j}^{t}\right)$ by using a vector of inputs $x_{j}^{t}=\left(x_{1 j}^{t}, \cdots, x_{m j}^{t}\right)$ at each time period t, $t=1,2, \cdots, T$. When multiple inputs are used to produce multiple outputs, Shephard's (1953) distance functions provide a functional characterization of the structure of production technology. The output distance function is defined on the output set, $\mathrm{P}(\mathrm{x})$, as:

$$
d_{0}(x, y)=\min \{\delta: y / \delta \in P(x)\} .
$$

The Malmquist productivity index is defined as:

$$
M_{o}=\sqrt{\frac{d_{o}^{t}\left(x_{o}^{t+1}, y_{o}^{t+1}\right) \times d_{o}^{t+1}\left(x_{o}^{t+1}, y_{o}^{t+1}\right)}{d_{o}^{t}\left(x_{o}^{t}, y_{o}^{t}\right) \times d_{o}^{t+1}\left(x_{o}^{t}, y_{o}^{t}\right)}} .
$$

$\mathrm{M}_{\mathrm{o}}$ measures the productivity change of $D M U_{o}$ between period $\mathrm{t}$ and $\mathrm{t}+1$. A value greater than one indicates positive productivity growth from period $t$ to period $t+1$. A value less than one indicates negative productivity growth from period t to period $\mathrm{t}+1$. The distance function $d_{o}(x, y)$ can be calculated using the output oriented DEA model (Färe et al., 1994a).

The Malmquist productivity index can be decomposed into two components: efficiency change (catch-up effect) and frontier shift (technological change).

Efficiency change: $E C=\left[\frac{d_{o}^{t+1}\left(x_{o}^{t+1}, y_{o}^{t+1}\right)}{d_{o}^{t}\left(x_{o}^{t}, y_{o}^{t}\right)}\right]$

Technology change: TC $=\sqrt{\frac{d_{o}^{t}\left(x_{o}^{t+1}, y_{o}^{t+1}\right) \times d_{o}^{t}\left(x_{o}^{t}, y_{o}^{t}\right)}{d_{o}^{t+1}\left(x_{o}^{t+1}, y_{o}^{t+1}\right) \times d_{o}^{t+1}\left(x_{o}^{t}, y_{o}^{t}\right)}}$

$\mathrm{M}_{\mathrm{o}}=\mathrm{EC} * \mathrm{TC}$.

According to Färe et al. (1994b), EC can be further decomposed into scale efficiency change and pure technology change. Ray and Desli (1997) pointed out the internal potential inconsistency problem of the further decomposition-both CRS and VRS models are used in the same decomposition. Consequently, the current paper uses the accepted decomposition shown in (8).

\subsection{Quality-incorporated Malmquist Productivity Index}

Färe et al. (1995) extended the Malmquist productivity index to incorporate quality attributes into it in a productivity analysis of Swedish pharmacies. Similar to the preference structure model, this is a useful model that has been rarely used in regulatory research and practice due to the lack of data on service quality. This study will extend the Malmquist productivity index to incorporate three quality attributes and test our hypothesis about the separation of the quality attributes.

Specifically, the technology set at $t$ is defined as $S^{t}=\left\{\left(x^{t}, y^{t}, a^{t}\right): x^{t}\right.$ can produce $y^{t}$ and $\left.a^{t}\right\}$

The output distance function of $D M U_{i}$ becomes:

$d_{i}^{t}\left(x^{t}, a^{t}, y^{t}\right)=\min \left\{\delta:\left(x^{t}, a^{t} / \delta, y^{t} / \delta\right) \in S^{t}\right\}$.

The quality change index between $\mathrm{t}$ and $\mathrm{t}+1$ is defined as:

\footnotetext{
${ }^{9}$ See Färe et al. (1994a) for detailed background and estimations based on DEA models.
} 


$$
Q_{i}^{t, t+1}\left(x^{t+1}, a^{t+1}, y^{t+1}, x^{t}, a^{t}, y^{t}\right)=\sqrt{\frac{d_{i}^{t}\left(x^{t}, a^{t+1}, y^{t}\right) \times d_{i}^{t+1}\left(x^{t+1}, a^{t+1}, y^{t+1}\right)}{d_{i}^{t}\left(x^{t}, a^{t}, y^{t}\right) \times d_{i}^{t+1}\left(x^{t+1}, a^{t}, y^{t+1}\right)}} .
$$

From equation (10) we can see, if $a^{t+1} \geq a^{t}$, then $Q^{t, t+1} \geq 1$.

The quality-incorporated Malmquist productivity index between period $t$ and $t+1$ can be expressed as:

$$
M_{q, i}^{t, t+1}\left(x^{t+1}, a^{t+1}, y^{t+1}, x^{t}, a^{t}, y^{t}\right)=\sqrt{\frac{d_{i}^{t}\left(x^{t+1}, a^{t+1}, y^{t+1}\right) \times d_{i}^{t+1}\left(x^{t+1}, a^{t+1}, y^{t+1}\right)}{d_{i}^{t}\left(x^{t}, a^{t}, y^{t}\right) \times d_{i}^{t+1}\left(x^{t}, a^{t}, y^{t}\right)}} .
$$

As before, this can be decomposed into technology change and efficiency change:

$$
M_{q, i}^{t, t+1}=\frac{d_{i}^{t+1}\left(x^{t+1}, a^{t+1}, y^{t+1}\right)}{d_{i}^{t}\left(x^{t}, a^{t}, y^{t}\right)} \sqrt{\frac{d_{i}^{t}\left(x^{t+1}, a^{t+1}, y^{t+1}\right) \times d_{i}^{t}\left(x^{t}, a^{t}, y^{t}\right)}{d_{i}^{t+1}\left(x^{t+1}, a^{t+1}, y^{t+1}\right) \times d_{i}^{t+1}\left(x^{t}, a^{t}, y^{t}\right)}} .
$$

Equation (11) can be also rewritten as:

$$
M_{q, i}^{t, t+1}=Q^{t, t+1}\left(x^{t+1}, a^{t+1}, y^{t+1}, x^{t}, a^{t}, y^{t}\right) \times \sqrt{\frac{d_{i}^{t}\left(x^{t+1}, a^{t+1}, y^{t+1}\right) \times d_{i}^{t+1}\left(x^{t+1}, a^{t}, y^{t+1}\right)}{d_{i}^{t}\left(x^{t}, a^{t+1}, y^{t}\right) \times d_{i}^{t+1}\left(x^{t}, a^{t}, y^{t}\right)}} .
$$

A further decomposition of (13) is obtained if the distance functions are multiplicatively separable in quality attributes and inputs/outputs; i.e., if

$$
d_{i}^{t+1}\left(x^{t+1}, a^{t}, y^{t+1}\right)=\mathrm{A}^{t+1}\left(a^{t}\right) \times \overline{d_{i}^{t+1}}\left(x^{t+1}, y^{t+1}\right) \text {. }
$$

The quality-incorporated Malmquist index can be expressed as:

$$
M_{q, i}^{t, t+1}=Q^{t, t+1}\left(x^{t+1}, a^{t+1}, y^{t+1}, x^{t}, a^{t}, y^{t}\right) \times \sqrt{\frac{\overline{d_{i}^{t}}\left(x^{t+1}, y^{t+1}\right) \times \overline{d_{i}^{t+1}}\left(x^{t+1}, y^{t+1}\right)}{\overline{d_{i}^{t}}\left(x^{t}, y^{t}\right) \times \overline{d_{i}^{t+1}}\left(x^{t}, y^{t}\right)}} .
$$

The second part in the right hand side of (15) is exactly the same as equation (6), which can be further decomposed into technical change and efficiency change according to (7). Thus,

$$
M_{q, i}^{t, t+1}=Q^{t, t+1} \times T C^{t, t+1} \times E C^{t, t+1} .
$$

If the productivity growth is the same with and without the imposition of separability (the Malmquist index calculated using equation (13) is similar to that calculated using equation (16)), the service quality aspect may be interpreted as consistent with the assumption of multiplicative separability.

\section{Empirical Model and Results}

We are now in a position to analyze the actual performance of 38 Peruvian EPS (Empresas Proveedoras de Servicios) from 1996-2001. Due to the missing value and extreme value problems, the sample size is 186 and involves an unbalanced panel. As Estache et al. (2004) note in their study, there are several possible ways to deal with the panel data within the context of DEA. One is to compute a frontier for each period and compare the efficiency of each firm relative to the frontier in each period. Another possibility is to treat the panel as a single cross-section (each firm year being considered as an independent observation) and pool the observations. This way, a single frontier is computed, and the relative efficiency of each firm in each period is calculated by reference to this single frontier. We follow this latter approach in order to increase the models' discriminating power. The CCR model is chosen because its result is highly correlated with that of BCC model and, more importantly, the Malmquist productivity index is built on the CRS model (Färe et al., 1994b). ${ }^{10}$

\footnotetext{
${ }^{10}$ As discussed earlier, the CCR model is based on constant return to scale while the BCC model is built on variable returns to scale.
} 


\subsection{Model Specification}

The models investigated here draw from the extensive benchmarking literature and earlier research on the characteristics of Peru's water industry (high water loss, low water quality, and excess staff). Model 1 (Basic Model) is based on simple physical inputs and outputs. Model 2 (Comprehensive) takes the service quality into account. Model 3 (Preference structure) applies a preference structure approach to DEA and weights quality even more heavily. It is clear that the service quality should not be neglected in the performance evaluation. Doing so causes the efficiency scores to change, although the new scores are still positively correlated with the original scores estimated in the basic model.

Model 1 (Basic): The inputs are the number of employees, the number of water connections, and network length. The outputs are volume of water billed and the number of customers. The number of employees (sum of the permanent workers and contract workers) is the measure of labor input. Because all of the companies in water industry of Peru are state-owned companies, excessive labor may be a serious problem (due to the interference of unions and politicians). For example, the mean value of the ratio of staff per 1000 connections is 6.04 , which is significantly higher than the mean value of the ratio (2.1) in developed countries (Tynan and Kingdom, 2002). The number of water connections is used as a proxy for capital inputs. Network length is used as a proxy for other operating costs. Specifically, network length is a crucial determinant of the administrative and maintenance costs, as well as depreciation. In addition, energy costs depend on network length (distance for pumping); furthermore, leakage (water losses) can be a larger issue when distances are significant. We therefore use network length as the third input of the model. Volume of water billed and the number of customers (two widely used outputs) are both incorporated into Model 1. ${ }^{11}$ Because the volume of water billed is highly correlated with revenue, revenue is not included as an output. ${ }^{12}$

Model 2 (Comprehensive): In model 2, we take service quality into account. Three service quality measures capture various dimensions of service quality: positive rate of chlorine tests, coverage of service, and continuity of service. The three service quality measures are treated as quality outputs in the comprehensive DEA models.

Coverage is defined as the population with access to water services as a percentage of the total population under the utility's nominal responsibility. It can be considered as one of the indicators of service quality because it is a direct measure of water availability to citizens in a municipality. Since water availability tends to be viewed as a citizen's "right," coverage reflects an important aspect of water service quality (Lin, 2005).

The percentage of samples with satisfactory residual chlorine and continuity of service are two of the three indicators used by SUNASS to evaluate the service quality. Due to the serious missing data problem, the percentage of water receiving chemical treatment is not included as an output. Percentage of samples with satisfactory residual chlorine is measured as a percentage of the sample where the residual chlorine (found in the water) satisfied the minimum requirements. Water is normally analyzed for many quality parameters; residual chlorine is chosen by SUNASS to show the degree of protection against bacterial contamination (http://www.ib-net.org). Substantial variation also exists for these two variables. The lowest satisfactory rate is only $4 \%$ while the minimum continuity of service is 5 hours per day. These patterns suggest the necessity of taking service quality into account when conducting benchmarking studies in developing countries like Peru. Therefore, these two variables are taken to be customer service

\footnotetext{
${ }^{11}$ Peru has a serious problem with water loss. According to official estimates, more than $40 \%$ of water is not billed, because of leaks or unauthorized connections. Therefore, we use water billed, not water delivered, as an output to measure the utility company's capability in system management, pipeline maintenance, and commercial practice.

12 Some utilities are also responsible for sewerage disposal. However, we cannot find data on physical output of treated sewerage. Therefore, in our study, we focus on water service. The sewerage inputs such as sewerage network length and sewerage connections are not included in the models. Due to data availability, most of the papers in the empirical literature do not include sewerage as an output. One exception is Tupper and Resende’s (2004) study of the Brazil water sector.
} 
quality variables. The summary statistics of the inputs and outputs used in the analysis are presented in Table 1.

[Table 1 here]

Model 3 (Preference Structure Weights): The SUNASS benchmarking scheme emphasizes social concerns: Six out of nine indicators are related to the customer service quality we defined above. Due to the lack of other studies that might establish the weights, we regard the current SUNASS benchmarking scheme as a proxy for regulators' preferences and give a weight of 2 (6/3) to each of the three customer service quality variables while giving a weight of 1 to the other outputs. ${ }^{13}$ The results of this preference structure DEA are then compared to the other models.

The models are summarized in Table 2.

[Table 2 here]

\subsection{Empirical Results}

\section{Efficiency Score (Model 2)}

For brevity, we only present the detailed estimation of the results from the comprehensive model (Model 2) in Table 3. ${ }^{14}$ The other detailed results are available from the authors upon request.

[Table 3 here]

\section{Correlation matrix of efficiency score and ranking}

The Pearson Correlation matrix of efficiency scores ${ }^{15}$ is shown in Table 4 in order to check the pattern of correlations associated with the different models. ${ }^{16}$

[Table 4 here]

The results shown in the correlation matrix are consistent with our expectation. The basic model has a very high correlation with the comprehensive model but a relatively low correlation with the preference weighted model. This shows that the "efficient" firms are not necessary the high quality suppliers. Specifically, the correlation between the basic model and comprehensive model is 0.825, suggesting that physical outputs (customers and water billed) play more important roles in determining firm efficiency in the original radial DEA model. After imposing the preference weights to the outputs (more weight to the three customer service quality variables), the correlation between basic model and weighted model falls to 0.311 while the correlation between comprehensive model and weighted model is 0.625. The result shows that the quality output dimensions now play a more important role in determining the firm efficiency for the weighted model (preference Model 3).

The above analysis showed that the regulators should have a clear picture about the targets (reducing cost, improving service quality, or advancing both objectives) and give explicit weights to the objectives. They can then choose the appropriate tools to conduct the benchmarking study.

\footnotetext{
13 In the current SUNASS benchmarking scheme, six indicators (compliance with the residual chlorine rule, continuity of service, percentage of water receiving chemical treatment, water coverage, sewerage coverage, and operating efficiency) are related to service quality. Since the SUNASS assigns an equal weight to the nine indicators, it implicitly imposes more (double) weight on service quality.

${ }^{14}$ To make the results more intuitive, the input-oriented efficiency scores are presented. The output-oriented efficiency scores are the inverse of the input-oriented efficiency scores in the CCR model.

${ }^{15}$ The Spearman's ranking correlation matrix generates very similar results.

16 The correlation coefficients encompass the efficiency observations of the pool samples (all companies for all years).
} 


\section{Malmquist Productivity Index and Quality-incorporated Malmquist Productivity Index}

In order to analyze the quality and efficiency change and test the assumption of quality separation, the Malmquist productivity index and quality-incorporated Malmquist productivity index are calculated, respectively. The calculation is based on the comprehensive model (Model 3). The Malmquist productivity index is calculated using equation (6), (8), (11), and (12). The quality-incorporated Malmquist productivity index is calculated using (10) and (13)-(16). Then the two indices are compared to one another. If the results (performance ratings) are similar, it means that the data are consistent with the assumption of multiplicative separability. The calculation of the Malmquist index requires a balanced panel data. Because of a serious missing data problem in year 1996 and 1997, the time period from 1998 to 2002 is utilized in the analysis. In addition, all the DMUs under evaluation are required to have complete data during this period. We exclude some problematic DMUs, and the sample size becomes 31 DMUs /year.

From Table 5, we can see that (on average) productivity has positive growth except for 1999-2000. Overall, productivity growth is quite modest. Frontier shift accounts for the productivity increase. This result is consistent with the finding by Saal and Parker (2006), who find that technical change (frontier shift) has been the dominant source of productivity growth in the English and Welsh water sectors. From Table 6 we can see that the quality-incorporated Malmquist productivity index depicts the same trend as in Table 5: on average, productivity growth is quite modest. We also see that on average the quality of service improved slightly during 1998-1999 and 1999-2000, but it declined during 2000-2001. In general, the average quality of service improved very slightly from 1998-2001, which suggests a lack of incentives for companies to improve their service quality under the current regulatory scheme. In the current regulatory scheme, no formal rewards or penalties are linked to SUNASS's ranking, and the ranking is not widely distributed.

\section{[Table 5 \& 6 here]}

Because quality improvement comes at a cost, municipal utilities may not have sufficient incentives to improve their service quality under this regulatory scheme. Some firms (like firm 3 and 8) have the highest quality growth during 1998-1999, followed by lower growth during 1999-2000 and the lowest quality growth during 2000-2001. For most other firms, the service quality level is quite stable over the time period.

Overall, these results show the importance of incorporating quality variables into a benchmarking scheme, publicly publishing the report, and linking the scheme to rewards/penalties. As was noted at the beginning of the paper, performance-based incentive standards such as quality-dependent price caps can be expressed as: $\mathrm{CPI}-\mathrm{X}+\mathrm{Q}$, where $\mathrm{CPI}$ is the consumer price index and the $\mathrm{X}$-factor is the productivity offset (based on the regulator's assessment of the potential productivity growth of the regulated firms). Q is a quality factor that allows the companies to increase/decrease rates or retain more/less revenue when quality improves/degrades. The quality change (QC) component provides useful information about Q. ${ }^{17}$ However, the QC index is based on the assumption of multiplicative quality separability (equations (14)-(16)), which has to be tested. Based on Färe et al. (1995), the Malmquist productivity index (MPI) is compared to the quality-incorporated Malmquist productivity index (QMPI). If the results are similar, the data are consistent with the assumption of multiplicative separability.

The Pearson correlation between MPI and QMPI is 0.89, and the non-parametric Spearman ranking correlation is 0.96 , both of which are significant at the 0.01 level. A two sample t-test assuming unequal variance is conducted. The null hypothesis that the sample means are equal cannot be rejected. $(\mathrm{t}=0.716) .{ }^{18}$ Therefore, the assumption of multiplicative separability is not rejected.

\footnotetext{
17 The regulator can also use other relevant information such as minimum quality standards and single dimension quality indicators to select appropriate Q targets.

18 The assumption underlying the t-test required that the populations be normally distributed. In order to test the robustness of the result, we conduct the Kruskal-Wallis Test, a non-parametric test. Again, the null hypothesis cannot be rejected.
} 


\section{Concluding Observations}

In emerging markets, the individuals who are developing and implementing public policy must give attention to service quality issues, including low coverage for many infrastructure services (Holt, 2005). As a tool to reduce the information gap between regulators and firms and introduce competition through regulation, yardstick regulation should include quality; otherwise low cost and low quality companies will be labeled as "efficient."

This study uses different types of DEA models (CCR and preference structure) to capture the regulator's preferences and illustrate the importance of including service quality measures and regulatory preference into benchmarking. The quality-incorporated Malmquist productivity index is then introduced in order to analyze quality change, efficiency change, and shifts in the frontier. Given the poor status of water service quality in Peru, the results show a slight improvement in service quality from 1998-2001, suggesting the lack of appropriate incentives for the companies to improve their service quality under the regulatory system utilized during this time frame. ${ }^{19}$

One additional use of benchmarking comparisons is to link managerial incentives more directly to performance. Some scholars (e.g., Shuttleworth, 2005; Cubbin, 2005) are skeptical of applying efficiency scores due to the sensitivity of the model specification and estimation. However, caution should not preclude the thoughtful application of appropriate models. The types of models presented here serve as catalysts for (1) collecting data to mitigate information asymmetries, (2) identifying sector trends and performance outliers, and (3) designing incentive-based managerial compensation plans (Mugisha et al., 2007). It is likely that far more waste has occurred due to poor management practices (and weak incentives) in developing countries than to the misapplication of infrastructure benchmarking techniques.

\section{Acknowledgements}

We thank the editor, Lawrence White, and two anonymous referees for very valuable and helpful comments. We also thank Chunrong Ai, David Sappington, and David Parker for helpful comments on earlier drafts. An early version of this paper was presented to the benchmarking working group of ADERASA (Asociación de Entes Reguladores de Agua y Saneamiento de las Américas or Association of Water and Sanitation Regulatory Entities of the Americas) at ADERASA's Conference (Buenos Aires, Argentina May 2004). The authors are responsible for any remaining errors of interpretation.

\section{References}

Ashton, J. K. (2000). Cost efficiency in the UK water and sewerage industry. Applied Economics Letters, 7(7), 455-458.

Banker, R. D., Charnes, A. \& Cooper, W. W. (1984). Some models for estimating technical and scale inefficiencies in data envelopment analysis. Management Science, 30(9), 1078-1092.

Berg, S., Lin, C. \& Tsaplin, V. (2005). Regulation of state-owned and privatized utilities: Ukraine electricity distribution company performance. Journal of Regulatory Economics, 28(3), 259-287.

Berg, S. \& Lin, C. (2006). Consistency in performance rankings: The Peru water sector, Applied Economics, forthcoming.

\footnotetext{
19 During this time period, SUNASS lacked instruments for rewarding or penalizing firms for performance. The overall weak record in service quality should be a signal to policy-makers that the "naming and shaming" approach (reflected in the nine-component scoring system) was not well publicized or that managers were not disciplined by local authorities when their utilities received "bad grades” from SUNASS.
} 
Burn, P., Jekins, C. \& Reichmann, C. (2006). The role of the policy framework for the effectiveness of benchmarking in regulatory proceedings. In T. Coelli \& D. Lawrence (Eds.), Performance measurement and regulation of network utilities. Northampton: Edward Elgar Publishers.

Carrington, R., Coelli, T. \& Groom, E. (2002). International benchmarking for monopoly price regulation: The case of Australian gas distribution, Journal of Regulatory Economics, 21(2), 191-216.

Charnes, A., Cooper, W. W. \& Rhodes, E. (1978). Measuring the efficiency of decision making units. European Journal of Operational Research, 2(6), 429-444.

Coelli, T. J. \& Perelman, S. (2000). Technical efficiency of European railways: A distance function approach. Applied Economics, 32(15), 1967-1976.

Cooper, W. W., Seiford, L. M. \& Zhu, J. (2004). Handbook on data envelopment analysis. Boston: Kluwer Academic Publishers.

Corton, M. L. (2003). Benchmarking in the Latin American water sector: The case of Peru. Utilities Policy, 11(3), 133-142.

Cubbin, J. \& Tzanidakis, G. (1998). Regression versus data envelopment analysis for efficiency measurement: An application to the England and Wales regulated water industry. Utilities Policy, 7(2), 75-85.

Cubbin, J. (2005). Efficiency in the water industry. Utilities Policy, 13(4), 289-293.

Estache, A. \& Rossi, M. A. (2002). How different is the efficiency of public and private water companies in Asia? The World Bank Economic Review, 16(1), 39-148.

\& Kouassi, E. (2002). Sector organization, governance, and the inefficiency of African water utilities. World Bank Policy Research Working Paper 2890.

Rossi, M. A. \& Ruzzier, C. A. (2004). The case for international coordination of electricity regulation: Evidence from the measurement of efficiency in South America. Journal of Regulatory Economics, 25(3), 271-295.

Perelman, S. \& Trujillo, L. (2004). Measuring efficiency quality tradeoffs: An application to Brazil's freight railways. VIIIth European Workshop on Efficiency and Productivity Analysis working group meeting.

Perelman, S. \& Trujillo, L. (2005). Infrastructure performance and reform in developing and transition economies: Evidence from a survey of productivity measures. World Bank Policy Research Working Paper 3514.

Färe, R. \& Lovell, C. A. K. (1978). Measuring the technical efficiency of production. Journal of Economic Theory, 19(1), 150-162.

Press.

Grosskopf, S. \& Lovell, C. A. K. (1994a). Production frontiers. New York: Cambridge University

Grosskopf, S., Norris, M. \& Zhang, Z. (1994b). Productivity growth, technical progress and efficiency change in industrialized countries. American Economic Review, 84(1), 66-83. 
, Grosskopf, S. \& Roos, P. (1995). Productivity and quality changes in Swedish pharmacies. International Journal of Production Economics, 39(1-2), 137-147.

Farsi, M. \& Filippini, M. (2004). Regulation and measuring cost-efficiency with panel data models: Application to electricity distribution utilities. Review of Industrial Organization, 25(1), 1-19.

Giannakis, D., Jamasb, T. \& Pollitt, M. (2005). Benchmarking and incentive regulation of quality of service: An application to the UK electricity distribution networks. Energy Policy, 33(17), 2256-2271.

Holt, L. (2005). Utility service quality—telecommunications, electricity, water. Utilities Policy, 13(3), 189-200.

Jamasb, T. \& Pollitt, M. (2001). Benchmarking and regulation: International electricity experience. Utilities Policy, 9(3), 107-130.

Kirkpatrick, C., Parker, D. \& Zhang, Y.-F. (2006). State versus private sector provision of water services in Africa: A statistical, DEA and stochastic cost frontier analysis. The World Bank Economic Review, forthcoming.

Knittel, C. (2002). Alternative regulatory methods and firm efficiency: Stochastic frontier evidence from the U.S. electricity industry. The Review of Economics and Statistics, 84(3), 530-540.

Lam, P.-L. \& Shiu, A. (2004). Efficiency and productivity of China's thermal power generation. Review of Industrial Organization, 24(1), 73-93.

Lin, C. (2005). Service quality and prospects for benchmarking: Evidence from the Peru water sector. Utilities Policy, 13(3), 230-239.

Lynch, J., Buzas, T. \& Berg, S. (1994). Regulatory measurement and evaluation of telephone service quality. Management Science, 40(2), 169-194.

Majumdar, S. (1997). Incentive regulation and productive efficiency in the U.S. telecommunications industry. Journal of Business, 70(4), 547-576.

Mugisha, S., Muhairwe, W. T. \& Berg, S. (2007). Using internal incentive contracts to improve water utility performance: The case of Uganda's NWSC. Water Policy, 9(3), 271-284.

Parker, D., Dassler, T. \& Saal, D. S. (2006). Performance benchmarking in utility regulation: Principles and problems. In M. Crew \& D. Parker (Eds.), International handbook on economic regulation. Northampton: Edward Elgar Publishers.

Ray, S. C. \& Desli, E. (1997). Productivity growth, technical progress and efficiency change in industrialized countries: Comment. American Economic Review, 87(5), 1033-1039.

Rossi, M. \& Ruzzier, C. (2000). On the regulatory application of efficiency measures. Utilities Policy, 9(2), 81-92.

Saal, D. S. \& Parker, D. (2000). The impact of privatisation and regulation on the water and sewerage industry in England and Wales: A translog cost function approach. Managerial and Decision Economics, 21(6), 253-268. 
\& Parker, D. (2001). Productivity and price performance in the privatised water and sewerage companies of England and Wales. Journal of Regulatory Economics, 20(1), 61-90.

\& Parker, D. (2006). Assessing the performance of water operations in the English and Welsh water industry: A lesson in the implications of inappropriately assuming a common frontier. In T. Coelli \& D. Lawrence (Eds.), Performance measurement and regulation of network utilities. Northampton: Edward Elgar Publishers.

Sappington, D. (2005). Regulating service quality: A survey. Journal of Regulatory Economics, 27(2), 123-154.

Shephard, R. W. (1953). Cost and production functions. Princeton: Princeton University Press.

Shleifer, A. (1985). A theory of yardstick competition. Rand Journal of Economics, 16(3), 319-327.

Shuttleworth, G. (2005). Benchmarking of electricity networks: Practical problems with its use for regulation. Utilities Policy, 13(4), 310-317.

Thanassoulis, E. (2000). DEA and its use in the regulation of water companies. European Journal of Operational Research, 127(1), 1-13.

Tupper, H. C. \& Resende, M. (2004). Efficiency and regulatory issues in the Brazilian water and sewage sector: An empirical study. Utilities Policy, 12(1), 29-40.

Tynan, N. \& Kingdom, B. (2002). A water scorecard: Setting performance targets for water utilities. Public Policy for the Private Sector, The World Bank Group, April 2002.

Uri, N. (2001). Productivity change, technical progress, and efficiency improvement in telecommunications. Review of Industrial Organization, 18(3), 283-300.

Wallsten, S. \& Kosec, K. (2005). Public or private drinking water? The effects of ownership and benchmark competition on U.S. water system regulatory compliance and household water expenditures. AEI-Brookings Joint Center Working Paper 05-05.

Zhu, J. (1996). Data envelopment analysis with preference structure. Journal of the Operational Research Society, 47(1), 136-150. 
Table 1: Sample Summary Statistics

\begin{tabular}{|l|l|l|l|l|}
\hline Variable & Mean & Standard Deviation & Minimum & Maximum \\
\hline Outputs & & & & \\
\hline Water Billed (m3) & 6786308 & 8285202 & 132917 & 32990614 \\
\hline Number of customers & 141379 & 179617 & 6908 & 809158 \\
\hline Coverage (\%) & 78 & 14 & 26 & 99 \\
\hline Positive rate of chlorine tests (\%) & 86 & 17 & 4 & 100 \\
\hline Continuity of service (hours/day) & 16 & 5 & 5 & 24 \\
\hline Inputs & & & & \\
\hline Number of Employees & 143 & 178 & 6 & 856 \\
\hline Number of Water Connections & 24329 & 30866 & 1003 & 148511 \\
\hline Network Length (km) & 258 & 349 & 7 & 1783 \\
\hline
\end{tabular}

Table 2: DEA Model Specification

\begin{tabular}{|c|c|c|c|}
\hline \multirow{4}{*}{ Inputs } & Model 1 (Basic Model) & Model 2 (Comprehensive) & Model 3 (Preference Structure) \\
\cline { 2 - 4 } & Number of Employees & Number of Employees & Number of Employees \\
\cline { 2 - 4 } & $\begin{array}{c}\text { Number of water } \\
\text { connections }\end{array}$ & Number of water connections & Number of water connections \\
\cline { 2 - 4 } & Network Length & Network Length & Network Length \\
\hline \multirow{4}{*}{ Outputs } & Volume of water billed & Volume of water billed & Volume of water billed \\
\cline { 3 - 4 } & Number of customers & Number of customers & Number of customers \\
\cline { 3 - 4 } & & Coverage & Coverage \\
\cline { 3 - 4 } & & Positive rate of chlorine tests & Positive rate of chlorine tests \\
\cline { 3 - 4 } & & Continuity of service & Continuity of service \\
\hline
\end{tabular}


Table 3: Efficiency Score of Model 2 (1996-2001)

\begin{tabular}{|c|c|c|c|c|c|c|}
\hline Firm/Year & 1996 & 1997 & 1998 & 1999 & 2000 & 2001 \\
\hline 1 & & & & 0.716 & & 0.726 \\
\hline 2 & & & & 1.000 & & 0.958 \\
\hline 3 & & & 0.995 & 1.000 & 1.000 & 1.000 \\
\hline 4 & & & & 0.846 & 1.000 & 1.000 \\
\hline 5 & & & & 1.000 & 1.000 & 0.992 \\
\hline 6 & 1.000 & 0.932 & 0.926 & 0.882 & 0.829 & 0.742 \\
\hline 7 & & & 1.000 & & & \\
\hline 8 & 0.915 & 0.981 & 0.966 & 0.974 & 0.924 & 0.854 \\
\hline 9 & 0.910 & & 0.689 & 0.751 & 0.604 & 0.829 \\
\hline 10 & & 0.843 & 0.810 & 0.884 & 0.766 & 0.737 \\
\hline 11 & & & 0.752 & 0.872 & 0.700 & 0.849 \\
\hline 12 & & & & 0.821 & 0.788 & 0.734 \\
\hline 13 & & 0.669 & 0.779 & 0.807 & 0.715 & 0.749 \\
\hline 14 & & 0.635 & 0.737 & 0.625 & 0.594 & 0.575 \\
\hline 15 & & & 0.684 & 0.758 & 0.729 & 0.729 \\
\hline 16 & 0.666 & 0.700 & 0.778 & 0.843 & 0.827 & 0.767 \\
\hline 17 & & 0.756 & 0.746 & 0.736 & 0.808 & 0.813 \\
\hline 18 & 0.567 & 0.556 & 0.547 & 0.570 & 0.418 & 0.562 \\
\hline 19 & 0.821 & 0.867 & 0.831 & 0.891 & 0.869 & 0.865 \\
\hline 20 & & & 0.645 & & & \\
\hline 21 & & & 0.611 & & & \\
\hline 22 & & & 1.000 & 0.803 & 0.685 & 0.677 \\
\hline 23 & & & 1.000 & 1.000 & 0.903 & 0.980 \\
\hline 24 & & 0.685 & 0.692 & 0.777 & 0.808 & 0.792 \\
\hline 25 & & & 0.762 & 0.842 & 0.791 & 0.749 \\
\hline 26 & 0.886 & 0.876 & 0.906 & 0.758 & 0.821 & 0.911 \\
\hline 27 & 0.838 & 0.820 & 0.763 & 1.000 & 1.000 & 0.944 \\
\hline 28 & 0.629 & 0.606 & 0.675 & 0.738 & 0.692 & 0.718 \\
\hline 29 & 0.861 & 0.765 & 0.725 & 0.683 & 0.692 & 0.679 \\
\hline 30 & & & 0.683 & 0.936 & 0.821 & 0.811 \\
\hline 31 & 0.784 & 0.743 & 0.702 & 0.775 & 0.808 & 0.741 \\
\hline 32 & & & 0.641 & 0.946 & 0.943 & 0.923 \\
\hline 33 & 0.636 & 0.639 & 0.673 & 0.907 & 0.791 & 0.839 \\
\hline 34 & 0.813 & 0.802 & 0.978 & 0.784 & 0.749 & 0.768 \\
\hline 35 & & & & 0.895 & 1.000 & 0.859 \\
\hline 36 & & & 0.829 & 0.808 & 0.837 & 0.920 \\
\hline 37 & & & 0.873 & 1.000 & 0.969 & 1.000 \\
\hline 38 & 0.799 & 0.784 & 0.739 & 0.720 & 0.698 & 0.676 \\
\hline 39 & & & 0.773 & 0.784 & 0.752 & 0.715 \\
\hline 40 & & 0.888 & 0.660 & 0.702 & 0.773 & 0.735 \\
\hline 41 & 0.963 & 0.846 & 0.825 & 0.939 & 0.740 & 0.769 \\
\hline 42 & 0.731 & 0.715 & 0.645 & 0.762 & 0.887 & 0.876 \\
\hline 43 & & & 0.659 & 0.689 & 0.711 & 0.710 \\
\hline
\end{tabular}


Table 4: Correlations of Efficiency Scores (order by Models 1, 2, 3)

\begin{tabular}{|c|ccc|}
\hline Correlation & Basic & Comprehensive & Preference \\
\hline Basic & 1 & & \\
Comprehensive & $0.825^{* *}$ & 1 & 1 \\
Preference & $0.311^{* *}$ & $0.625^{* *}$ & 1 \\
\hline
\end{tabular}

** Correlation is significant at the 0.01 level (2-tailed). 
Table 5: Malmquist Indexes, Efficiency Change and Frontier Shift (1998-2001)

\begin{tabular}{|c|c|c|c|c|c|c|c|c|c|c|c|c|}
\hline \multirow[b]{2}{*}{ Company } & \multicolumn{3}{|c|}{ 1998-1999 } & \multicolumn{3}{|c|}{$1999-2000$} & \multicolumn{3}{|c|}{ 2000-2001 } & \multicolumn{3}{|c|}{1998 vs. 2001} \\
\hline & $\begin{array}{l}\text { Malmquist } \\
\text { Index }\end{array}$ & $\begin{array}{l}\text { Efficiency } \\
\text { Change }\end{array}$ & $\begin{array}{l}\text { Technology } \\
\text { Change }\end{array}$ & M & EC & TC & M & EC & TC & M & EC & TC \\
\hline 3 & 1.107 & 1.000 & 1.107 & 1.071 & 1.000 & 1.071 & 1.361 & 1.000 & 1.361 & 1.576 & 1.000 & 1.576 \\
\hline 6 & 0.919 & 1.000 & 0.919 & 0.948 & 1.000 & 0.948 & 0.923 & 0.928 & 0.994 & 0.884 & 0.928 & 0.952 \\
\hline 8 & 1.061 & 1.000 & 1.061 & 1.002 & 1.000 & 1.002 & 0.933 & 1.000 & 0.933 & 0.985 & 1.000 & 0.985 \\
\hline 10 & 1.246 & 1.061 & 1.175 & 0.889 & 1.000 & 0.889 & 0.978 & 0.790 & 1.237 & 1.087 & 0.838 & 1.297 \\
\hline 13 & 1.034 & 0.925 & 1.117 & 0.878 & 0.937 & 0.937 & 1.036 & 1.053 & 0.983 & 0.980 & 0.914 & 1.073 \\
\hline 14 & 0.797 & 0.812 & 0.982 & 0.922 & 0.934 & 0.988 & 0.968 & 0.994 & 0.974 & 0.686 & 0.754 & 0.910 \\
\hline 15 & 1.137 & 0.980 & 1.160 & 0.948 & 0.959 & 0.989 & 0.971 & 0.930 & 1.044 & 1.043 & 0.874 & 1.193 \\
\hline 16 & 1.065 & 1.003 & 1.063 & 0.908 & 1.000 & 0.908 & 0.926 & 1.000 & 0.926 & 0.945 & 1.003 & 0.942 \\
\hline 17 & 0.852 & 0.837 & 1.018 & 1.182 & 1.194 & 0.989 & 0.917 & 0.984 & 0.933 & 0.973 & 0.984 & 0.989 \\
\hline 19 & 1.052 & 1.000 & 1.052 & 1.014 & 1.000 & 1.014 & 1.023 & 1.000 & 1.023 & 1.068 & 1.000 & 1.068 \\
\hline 22 & 0.608 & 0.886 & 0.686 & 0.804 & 0.886 & 0.908 & 0.952 & 0.935 & 1.019 & 0.479 & 0.734 & 0.653 \\
\hline 23 & 1.159 & 1.000 & 1.159 & 0.826 & 1.000 & 0.826 & 1.095 & 1.000 & 1.095 & 1.022 & 1.000 & 1.022 \\
\hline 24 & 1.143 & 0.996 & 1.148 & 1.060 & 1.125 & 0.942 & 0.977 & 0.954 & 1.024 & 1.131 & 1.069 & 1.058 \\
\hline 25 & 1.154 & 1.012 & 1.141 & 0.932 & 0.964 & 0.967 & 0.925 & 0.925 & 1.000 & 1.021 & 0.902 & 1.132 \\
\hline 26 & 0.798 & 0.811 & 0.983 & 1.061 & 1.114 & 0.952 & 1.115 & 1.078 & 1.034 & 0.969 & 0.974 & 0.995 \\
\hline 27 & 1.341 & 1.123 & 1.194 & 0.997 & 1.000 & 0.997 & 0.920 & 1.000 & 0.920 & 1.281 & 1.123 & 1.141 \\
\hline 28 & 1.121 & 1.017 & 1.103 & 0.978 & 1.019 & 0.959 & 1.033 & 1.139 & 0.908 & 1.162 & 1.180 & 0.985 \\
\hline 29 & 1.020 & 0.902 & 1.131 & 0.989 & 1.011 & 0.978 & 0.972 & 1.003 & 0.969 & 0.990 & 0.915 & 1.082 \\
\hline 30 & 1.312 & 1.186 & 1.106 & 0.852 & 0.923 & 0.923 & 0.979 & 0.962 & 1.018 & 1.203 & 1.052 & 1.143 \\
\hline 31 & 1.114 & 1.084 & 1.027 & 1.046 & 1.142 & 0.916 & 0.908 & 0.935 & 0.971 & 1.098 & 1.158 & 0.948 \\
\hline 32 & 1.599 & 1.182 & 1.353 & 0.968 & 1.000 & 0.968 & 0.992 & 1.000 & 0.992 & 1.441 & 1.182 & 1.220 \\
\hline 33 & 1.279 & 1.083 & 1.182 & 0.824 & 0.986 & 0.836 & 1.094 & 1.014 & 1.079 & 1.177 & 1.083 & 1.087 \\
\hline 34 & 0.901 & 0.826 & 1.091 & 0.930 & 1.034 & 0.900 & 1.027 & 1.011 & 1.015 & 0.878 & 0.863 & 1.018 \\
\hline 36 & 1.031 & 0.815 & 1.264 & 1.007 & 1.089 & 0.925 & 1.106 & 1.092 & 1.012 & 1.139 & 0.970 & 1.174 \\
\hline 37 & 1.175 & 1.000 & 1.175 & 0.896 & 1.000 & 0.896 & 1.103 & 1.000 & 1.103 & 1.136 & 1.000 & 1.136 \\
\hline 38 & 1.025 & 1.000 & 1.025 & 0.950 & 1.040 & 0.914 & 0.936 & 0.958 & 0.977 & 1.000 & 0.996 & 1.003 \\
\hline 39 & 1.081 & 0.971 & 1.113 & 0.917 & 1.031 & 0.889 & 0.931 & 0.924 & 1.007 & 1.005 & 0.925 & 1.086 \\
\hline 40 & 1.067 & 0.843 & 1.265 & 1.074 & 1.193 & 0.900 & 0.917 & 0.900 & 1.018 & 1.129 & 0.906 & 1.246 \\
\hline 41 & 1.123 & 1.077 & 1.043 & 0.729 & 0.755 & 0.966 & 1.072 & 1.173 & 0.913 & 0.930 & 0.953 & 0.976 \\
\hline 42 & 1.220 & 0.987 & 1.235 & 1.186 & 1.281 & 0.926 & 0.995 & 0.959 & 1.038 & 1.537 & 1.213 & 1.268 \\
\hline 43 & 1.058 & 0.941 & 1.124 & 1.017 & 1.047 & 0.971 & 0.985 & 1.050 & 0.937 & 1.069 & 1.036 & 1.032 \\
\hline Average & 1.084 & 0.979 & 1.103 & 0.962 & 1.021 & 0.942 & 1.002 & 0.990 & 1.015 & 1.065 & 0.985 & 1.077 \\
\hline
\end{tabular}


Table 6: Malmquist Indexes with Quality Change

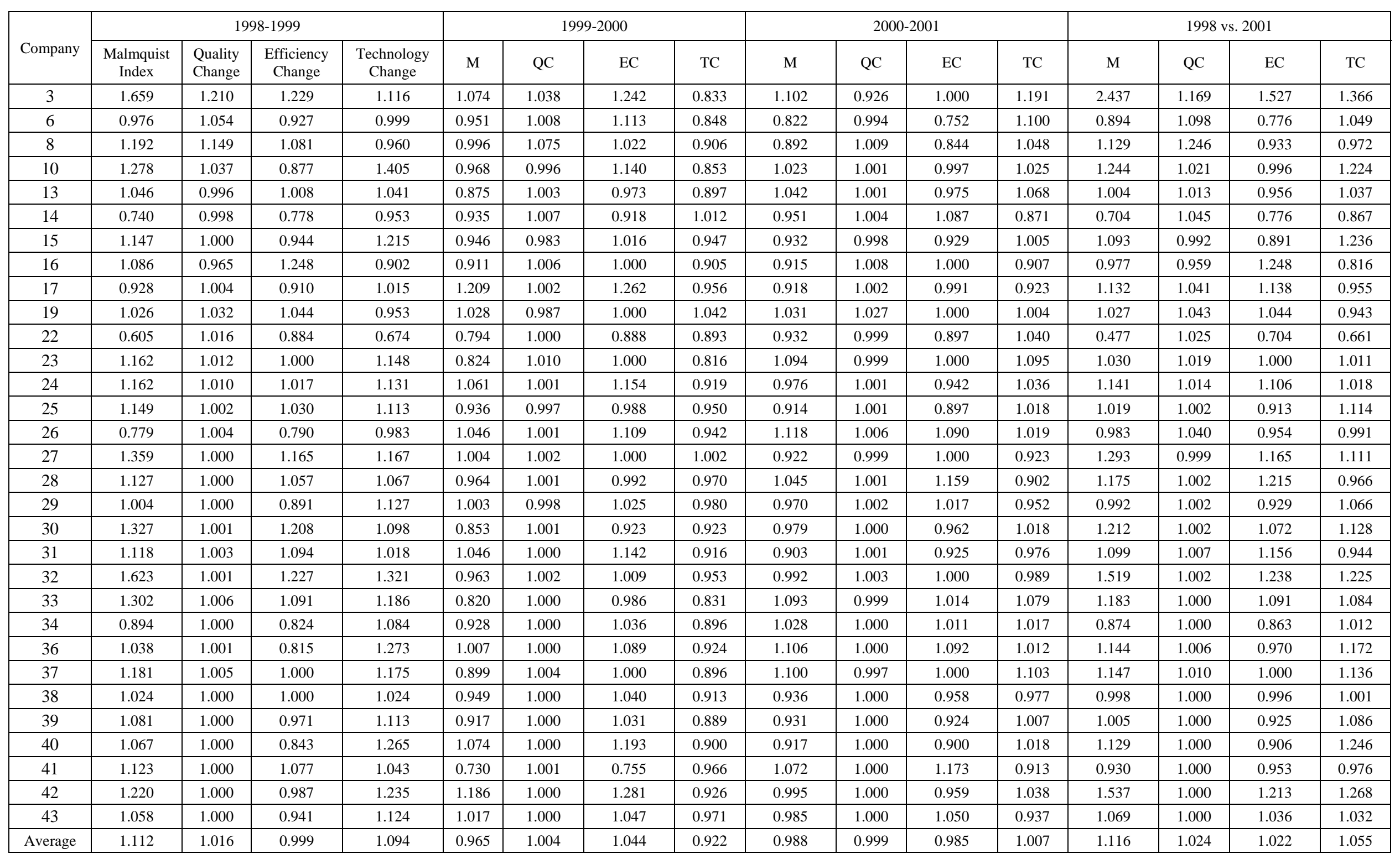

